\title{
Channels of labour supply responses of lone parents to changed work incentives
}

\section{By Xiaodong Gong ${ }^{\star}$ and Robert Breunig ${ }^{\dagger}$}

${ }^{*}$ University of Canberra, Australian National University, and IZA; e-mail: xiaodong.gong@natsem.canberra.edu.au

†Crawford School of Public Policy, Australian National University; e-mail: robert.breunig@anu.edu.au

\begin{abstract}
In this article, we investigate the response of female lone parents to two reforms to the welfare system in Australia. Using childless single women as a control group, we find the first set of reforms increased hours worked substantially through job changes. The second set had much more modest effects on hours, which included a decrease in hours worked for those with children younger than six, but did effect an increase in participation. Our results highlight the heterogeneity of response of lone parents to welfare interventions and provide support for the importance of accounting for fixed costs and for within-job rigidities.
\end{abstract}

JEL classifications: C23, H31, I38, J13, J22.

\section{Introduction}

The focus of this article is the means by which welfare recipients, in particular single mothers with children, respond to changed work incentives. The first contribution is to illustrate that not all policies designed to increase work incentives affect all groups of workers and potential workers uniformly. Hours changes in response to changed incentives vary by age and number of children and single mothers' educational levels. We also show that non-workers and those already working respond to different incentives. Our findings illustrate that fixed costs of working may be an important element in modelling labour supply.

A second contribution is our focus on job changes as a channel of adjustment. The standard labour supply model assumes that workers can freely choose their utility-maximizing hours of work at any given wage. Under this model, one would only observe changes in hours of work by an employee if she received a higher (or lower) wage offer or if her working hour preferences changed. New welfare rules for lone mothers change their optimal (preferred) working hours. The standard model implies that there should be no need to change jobs to realize these new preferred working hours. Using panel data we look at the means by which single mothers realize their new preferred working hours. We find that changes in working hours are primarily achieved through changing jobs, which we take as evidence 


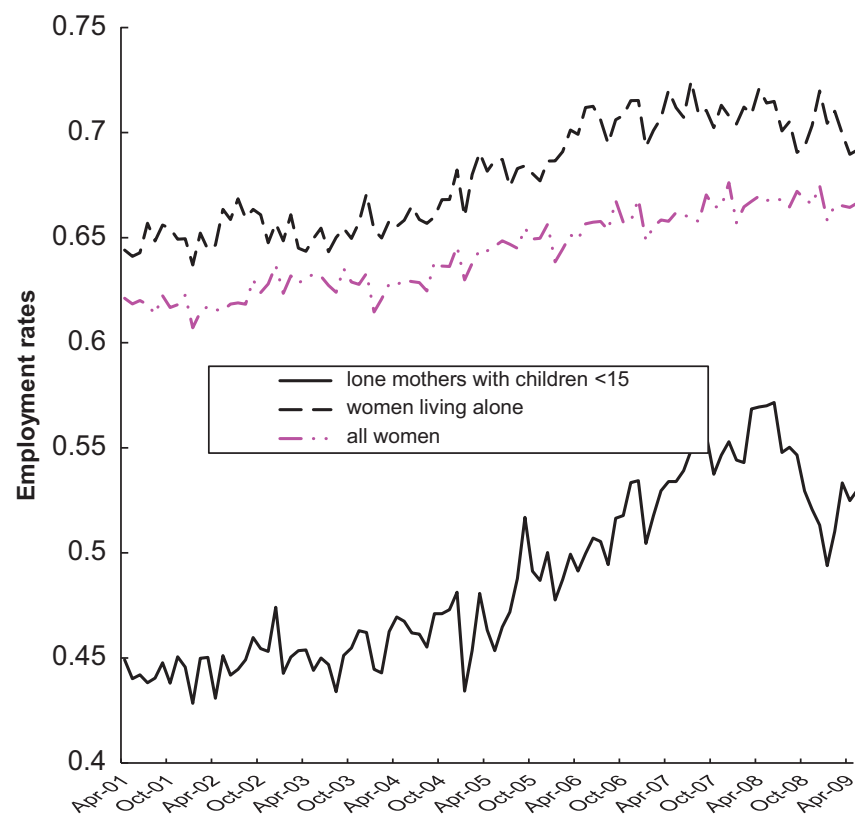

Months

Fig. 1 Employment rates of lone mothers versus other groups of women

Source: 6291.0.55.001-Labour Force, Australia, Detailed-Electronic Delivery (August 2011).

for in-work rigidities in the Australian labour market. Channel of response also differs by educational level.

Finally, we examine how the response of lone mothers differed from that of married mothers. ${ }^{1}$ Both groups were affected by the policy changes we study, but some policy changes applied differently to lone mothers. By looking at the differential response, we improve our understanding of the response of lone parents to the reforms.

Together, our results highlight that policy design should take into account the heterogeneity of workers and potential workers and their different responses to different types of incentives.

As in many countries, labour supply of women with children in Australia, particularly lone mothers, is lower than other demographic groups. Figure 1 shows, however, that since about 2005, the employment rate of lone mothers has been increasing. At the same time, two sets of reforms were introduced to encourage labour supply through reducing work disincentives associated with transfer programs and assisting families with the cost of child care. Lone mothers were particularly targeted in the second of these reforms. The first reform, introduced in

\footnotetext{
${ }^{1}$ Throughout we use the term married to refer to women in couple-headed households including those who are officially married and those who are in de facto relationships.
} 
2004, reduced the rate at which benefits were reduced as income increases (the taper rate) for family tax credits in Australia. The second set of reforms, introduced across 2006-2007, consisted of two policy changes: the rules for qualifying for the primary income support payment for single parents were tightened by restricting the age of the youngest child in the household and a new tax rebate for child care expenses took effect. These reforms are described more fully below.

Is the observed increase in lone mothers' labour supply a coincidence or can it be attributed, at least in part, to those reforms? To answer this question we look separately at the changes in working hours for those already working and the effect on participation for non-workers and for all workers. For working hours, we separate hours changes for those who stay in the same job and those who change jobs. In doing so, we allow for the presence of rigidities in the Australian labour market. The literature has shown that workers' choices of hours within a job are limited and wage and hours are often 'packaged' together-see, for example, Ham (1982), Moffitt (1984), Lundberg (1985), Altonji and Paxson (1988, 1992), Stewart and Swaffield (1997), and Euwals (2001). ${ }^{2}$ As discussed in Altonji and Paxson (1988), when hours are constrained within a job, a worker may be able to increase her utility by jumping to another job that is closer to her supply curve, even without any wage change. Altonji and Paxson (1992) show that hours changes (and changes in preferred hours) are significantly larger for quitters than nonquitters. Blundell et al. (2008), whose approach we largely follow in conducting our analysis, studied labour supply changes for single British females in response to three reforms in the 1990s that affected work incentives. They conclude that the reforms led to a significant increase in single mothers' hours of work and that the adjustments were largely through job changes.

Using childless women as a control group, we use a quasi-experimental approach and the difference-in-differences estimator to evaluate the reforms. One advantage of this approach is that ex ante predictions of reform on the basis of partial equilibrium models ignore indirect effects of reform, the demand side of the market, and the impact of other markets. In our case, for example, child care providers may increase prices in response to increased subsidies, and this would dampen the effects of the reforms we study. ${ }^{3}$ A drawback of this approach, which we discuss in more detail later, is the potential inadequacy of the control group. In particular, the labour response of childless women may not be a good proxy for the response of single mothers in the absence of the reforms.

Many studies have used similar approaches to evaluate reforms in the UK, the USA, Canada, and Australia. Eissa and Liebman (1996), Ellwood (2000), Hotz et al. (2002), and Eissa and Hoynes (2004) studied the labour market impact of the Earn

\footnotetext{
${ }^{2}$ Blundell and MaCurdy (1999) have reviewed this literature.

${ }^{3}$ We are unaware of any ex ante studies of the reforms we analyse in this article.
} 
Income Tax Credit (EITC) reforms during the 1980s and 1990s in the USA. These studies confirmed that the EITC can explain a significant part of the rise in employment of women with children in the USA over those periods (see Hotz and Scholz 2003 for more discussion). In the UK, the effects of reforms related to Family Credit and Working Families' Tax Credit were investigated by Gregg and Harkness (2003), Francesconi and Klaauw (2004, 2007), Leigh (2005), Blundell et al. (2005, 2008), and Brewer et al. (2006). Card and Robins (1998) examined the 'Self-Sufficiency' experiment in Canada. A consensus amongst these studies is that those programs led to increases in employment of women with children. Yet Blundell et al. (2008) seem to be the only ones who studied the mechanism through which these effects are achieved. In Australia, Doiron (2004) uses repeated cross-sections of data from the Income Distribution Survey to evaluate the impact of the 1987 reform of Single Parent Pension. She finds that the reform increased lone mothers' labour force participation, but their hours of work decreased. However, without longitudinal data, she was unable to investigate how adjustment occurred.

We find evidence that the reforms increased working hours of workers and subsequent employment of non-workers. The adjustment in hours of work was largely through changing employers, providing evidence of labour market rigidities. This is similar to what was found in the UK in the 1990s. The 2004 reform had positive effects on working hours of lone mothers, but only through job changes. The effects were concentrated amongst lone mothers with lower levels of education and with fewer and older children. The 2004 reform did not move non-workers into employment. In contrast, the 2006 reform affected the employment probability of those who were not working prior to the reform. As the 2006-2007 reforms had both a work incentive aspect and a lowering of the cost of working (through the child care tax rebate) aspect, this conforms to our expectations. The increase in participation was particularly important for lone mothers with lower education levels and with fewer and older children.

Comparing the response of lone mothers to married women, we find no significant difference for the 2004 reforms. This is not surprising because those reforms affected all families with children. Participation effects for lone mothers are larger than for married women in response to the 2006 reforms. Again, this conforms to our expectations as those reforms had common elements which affected both groups but also included reforms to increase work incentives specifically for lone mothers. However, we are unable to disentangle whether the difference is due to a different response to the common aspects of the reforms or whether it is due to the different nature of the reforms for the two groups.

The rest of the article is organized as follows, Section 2 summarizes the principal government benefits paid to lone parents and the reforms to those payments introduced since 2004. The approach, identifying assumptions, and model specification are discussed in Section 3. We present the data in Section 4. The results are summarized in Section 5, and we discuss sensitivity analysis and robustness checks in Section 5.4. We conclude in Section 6. 


\section{Government support to lone parents in Australia}

\subsection{Transfer payments to lone parents before 2004}

Prior to the 2004-5 financial year, ${ }^{4}$ lone parents in Australia were entitled to the following payments: Parenting Payment Single (PPS) ${ }^{5}$ Family Tax Benefit A (FTBA) and Family Tax Benefit B (FTB-B); and if they used formal child care, Child Care Benefit (CCB). ${ }^{6}$ Lone-parent families may be eligible for other payments depending on their specific circumstances (such as disability support), but these three means-tested payments represent the main source of income support to lone parents before 2004 .

PPS is a pension paid to low-income, single parents with children under the age of 16. One important contextual aspect of the Australian income support system is that 'pensions' are more generous than 'allowances', and this difference has grown over time because pensions are indexed to Average Weekly Earnings (AWE), whereas allowances are indexed to the Consumer Price Index which, for the past 20 years, has risen less quickly than AWE. In the second set of reforms, some lone parents who received PPS were moved from a pension to an allowance which was both less generous at that point in time and growing more slowly over time. In 2003 , PPS was paid at a maximum rate of $\$ 440.30$ per fortnight (or $\$ 11,447.8$ per annum) whilst the maximum amount of any allowance was $\$ 411.10$ per fortnight (or $\$ 10,688.60$ per annum). ${ }^{7}$

FTB-A and FTB-B are family assistance payments, excluded from taxable income, paid to families with children under age 16 or full-time students under 19. (FTB-A was, at that time, paid to families with dependent children up to the age of 24 but now stops at the end of the calendar year in which the dependent student turns 19.) FTB-B does not depend on the number of children in the household nor on employment status and is not means-tested for lone parents. ${ }^{8}$ FTB-A, on the other hand, depends on the age and number of children and is means-tested. As illustrated by the broken line in Fig. 2, in 2003, a lone parent with one child under 13 could get $\$ 4,001.80$ of FTB-A per annum if her annual private income was below $\$ 31,755$. After that, for each extra dollar she earns, her FTB-A entitlement was reduced by 30 cents (the 'taper rate') until reaching $\$ 1,695$ per annum. Her FTB-A entitlement would stay at that level until her income reached $\$ 39,464$

\footnotetext{
${ }^{4}$ The Australian financial year runs from 1 July to 30 June.

${ }^{5}$ Low-income couples were eligible for Parenting Payment Partnered (PPP), another type of income support payment.

${ }^{6}$ This is a means-tested program that reduces the hourly cost of formal child care. The scheme remained largely the same over the past decade, so it is not the focus of the analysis.

${ }^{7}$ All dollar figures are in Australian dollars. On 30 June 2004, the Australian dollar was equal to 0.57 euro or US\$0.69. In June 2013, the Australian dollar was equal to 0.71 euro or $\$$ US0.95.

${ }^{8}$ In 2003, a lone parent received $\$ 2,920$ per annum of FTB-B if her youngest child was under age five and $\$ 2,037$ otherwise.
} 


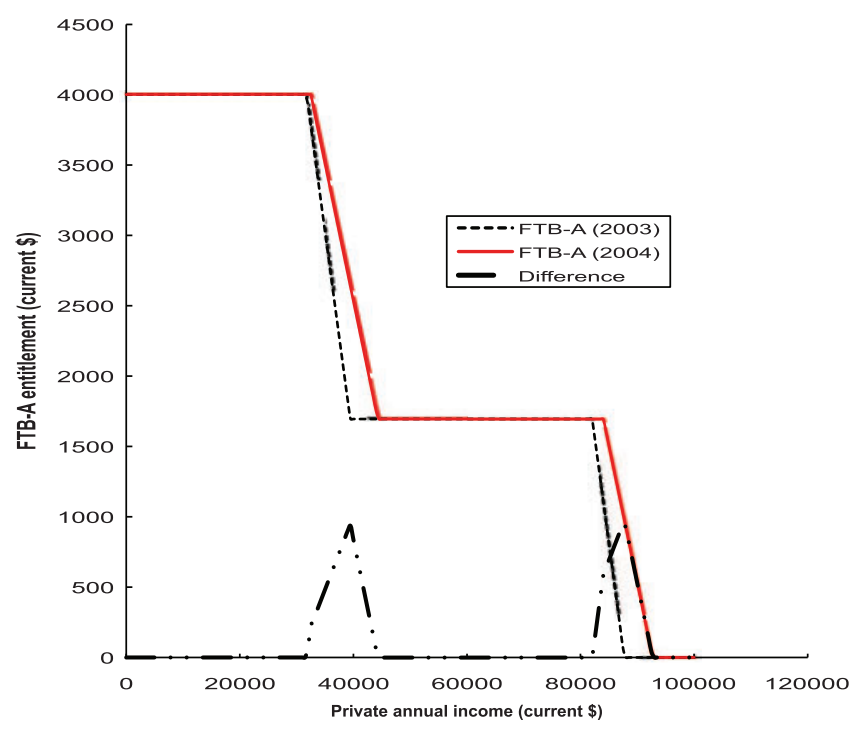

Fig. 2 FTB-A entitlement and annual income for a lone parent with one child under age 13.

before it is again reduced by 30 cents for every additional dollar earned until reaching an entitlement of zero dollars at an income level of $\$ 82,052$. $^{9}$

\subsection{Three reforms since 2004}

There was one substantial reform introduced in the 2004-5 financial year and two reforms in the 2006-7 financial year. Our analysis has two parts: the first reform and the combination of the second and third contemporaneous reforms.

The 2004-5 reform was part of a legislative package entitled 'More help for families'. The Australian government lowered the taper rates of the means-tests for FTB-A and FTB-B from $30 \%$ to $20 \% .{ }^{10}$ The change in the taper rate is captured by the movement from the dotted line to the solid line in Fig. 2. This change is equivalent to boosting the wage of a working lone mother by $10 \%$ if her annual income is in the tapering region. The thick dot and dash line in Fig. 2 shows the change from 2003 to 2004 in FTB-A entitlement at each level of income.

\footnotetext{
${ }^{9}$ Lone parents who qualify for FTB-A also qualify for rent assistance if they are renting. Taper rates for rent assistance are the same as those for FTB-A because rent assistance is treated like a top-up of the FTB-A payment.

${ }^{10}$ Lone mothers, not subject to means testing for FTB-B, were not affected by this latter change; however, couple-headed households were. An annual supplement of $\$ 600$ per child was also introduced to the maximum payment rate of FTB-A for all households from July 2004. For comparability between 2003 and 2004 we do not show the $\$ 600$ supplement on Fig. 2. This supplement provides a negative work incentive for those not working or at low incomes and is an offsetting effect, which is part of the 2004 reform that we analyse.
} 
In Figure A1 in the appendix, we show the distribution of annual earnings for working lone parents in our 2003 data. We can see from this non-parametric, kernel density estimate that more households are affected by the change in the taper rate that happens in the lower part of the income distribution, but there is mass in the distribution at both income points where the reform occurs. If the elasticity of labour supply with respect to own wage is positive, this reform should lead to an increase in hours worked of lone mothers. The effect of this reform is even larger for those receiving rent assistance because of its treatment as a top-up to FTB-A (see note 9).

The 2006-7 reforms consisted of two policy changes. First, PPS eligibility rules were tightened. ${ }^{11}$ Under the new rules, new single-parent claimants were only eligible for PPS if their youngest child was under eight years of age. Previously, single parents were eligible if their youngest child was under age 16. New income support claimants with children aged eight or older no longer qualified for PPS (a pension) but instead could receive New Start Allowance (NSA)—a less generous unemployment benefit that also includes a more onerous training and job search requirement. ${ }^{12}$ Not all single parents were affected as those on the PPS program prior to the changes were treated under the old rules provided that their relationship status remained unchanged and that they never had any payments cancelled. The PPS payments continued to these individuals as before, however, they faced a more onerous training and job search requirement from 1 July 2007 or once their youngest child turned seven, whichever happened last. ${ }^{13}$ Importantly, single parents who were already working were unaffected by these changes.

Eligibility rules for PPP, paid to couple-headed households, were also tightened, although the changes were much smaller than the changes to PPS. The main change was that new applicants to PPP could only receive the payment whilst their youngest child was aged less than six years (compared to the previous cut-off of eight). There was no change in payment rate as PPP and NSA were paid at the same rates, but training and job search requirements are more rigorous for those receiving NSA compared to PPP. PPP recipients did not benefit from any of the other benefits (see note 6) that PPS recipients lost in the reforms. Thus, a much greater percentage of PPS recipients were affected by these reforms than PPP recipients.

The second reform in 2006-7 was the introduction of the Child Care Tax Rebate (CCTR). Families of all types were able to claim $30 \%$ of out-of-pocket costs (in excess of CCB payments) for approved child care up to a maximum of $\$ 4,000$ per child per annum. Households were able to claim CCTR for two years prior to the reform back to the 2004-5 financial year when they filed their tax return for the

\footnotetext{
${ }^{11}$ This was part of the legislative package 'Welfare to Work'.

${ }^{12}$ Switching from PPS to NSA also involved the loss of several other benefits, including access to the Pensioner Concession Card, a Pensioner Education Supplement for those in approved education, and the Pharmaceutical Allowance for many participants.

${ }^{13}$ In practice this was phased in over 12 months from that date; see Fok and McVicar (2012).
} 
2005-6 financial year (after 1 July 2006). Most households file their tax return between July and October, thus the first payment only reached families in late 2006. Initially, CCTR was introduced as a tax offset, so only families with a tax liability could benefit. After the 2006-7 financial year, it was changed into a transfer payment which households could access even in the absence of a tax liability. ${ }^{14}$ The labour market effects of this reform are ambiguous. Lowering child care costs lowers the costs of working, so this may encourage people to work more. However, there is also an indirect income effect as the effective decrease in child care costs might result in a lowering of labour supply.

As the first reform had a prolonged phase-in and the second reform involved a delayed payment through the tax system, we think of this reform as being introduced across the two-year period 2006 to 2007.

This period coincided with other policy changes that may have some minor interactions with the reforms we study. A 'Maternity Payment' (later relabeled the 'Baby Bonus') of $\$ 3,000$ was introduced from July 2004, and increased to $\$ 4,000$ from July 2006 and to $\$ 5,000$ from July 2008. This may affect the fertility and labour supply behaviour of some women. ${ }^{15}$ Our main conclusions rely on comparison of women whose parental status is constant across consecutive years, so we are comparing groups whose behaviour was not affected by this policy. There were some minor participation requirements for small sub-groups of PPS recipients introduced in 2003. We keep this contextual background in mind when analysing our results.

\section{Approach}

\subsection{Identification}

We use single, childless women as a comparison group for single mothers and the difference-in-differences approach to identify the policy effects. ${ }^{16}$ Many studies use childless women as a control group for lone mothers (see Eissa and Liebman, 1996; Gregg and Harkness, 2003; Francesconi and Klaauw, 2007; Blundell et al., 2008). The first key identifying assumption of this approach is that single, childless women are not affected by the reforms. Given that we are analyzing administrative rule changes that did not apply in any way to single, childless women, this assumption would appear to be met. The second key identifying assumption is that no other factors affected the two groups differently over the same period. This assumption requires more scrutiny.

We check the validity of our approach and of the comparison group in a number of ways. We compare the characteristics of our treatment and control group; we use

\footnotetext{
${ }^{14}$ The child care rebate was increased to $50 \%$ and paid quarterly (instead of annually) from July 2008 .

${ }^{15}$ The fertility effects appear to be small, particularly for our treatment and control groups; see Parr and Guest (2011).

${ }^{16}$ For discussion of the approach, see Ashenfelter (1978), Heckman and Robb (1985), Meyer (1995), Blundell and MaCurdy (1999), and Angrist and Kruger (1999).
} 
non-parametric matching; and we restrict the sample in various ways, all of which are described in Section 5. Our results are robust to these modifications, though all of them maintain the (conditional) common trends assumption for at least some sub-samples of our comparison and control groups. The period that we analyse was one of robust economic and job growth in Australia, the benefits of which were spread across most demographic groups. In our data, working single mothers have many characteristics which are similar to working single, childless women (see Section 4), which would appear to make them a good control group. However, single, childless women have much higher rates of employment initially, which means there is less scope for increased employment participation. Wage elasticities (see Kalb, 2010) have been shown to be much higher for single mothers than for single, childless women. We conduct placebo tests to check if our results are associated with the timing of the reforms or whether they are just reflecting these systematic differences between the two groups independently of any effect of the reform. These tests suggest that we are picking up an effect of the reforms; see Section 5.4.

Some studies, such as Doiron (2004), use married mothers as a control group. This would be inappropriate in our case because married mothers were affected by the reforms we analyse. Nonetheless, the reforms applied differently to single and to married mothers. Whilst single, childless women remain the best control group available to identify the effect of the total reform package on single mothers, we also present estimates using married mothers as a control group to identify the differential effect of those parts of the reform that applied exclusively to single mothers. These are discussed later.

To avoid to separately modelling the labour supply of women who re-partner, we restrict our estimation sample to those individuals who are lone mothers in consecutive waves and those who are single, childless women in consecutive waves. ${ }^{17}$ We analyse the impact of the reforms on women whose relationship and motherhood status remains constant. We include in the sample mothers who have additional children.

One issue for comparability of our treatment and control groups is that the changing ages of children in the lone-mother households across time will have labour supply effects which the single, childless women will not experience. To deal with this, we control for the changes in the number of children in different age ranges in the household. The age ranges are chosen to reflect differing care demands (including school eligibility) for children of different ages. We also, in the sensitivity tests presented later, restrict the sample to lone mothers whose children remain in the same age group before and after the policy change. Our results do not appear to be sensitive to this issue.

\footnotetext{
${ }^{17}$ We drop 47 women who go from being single and childless to having a child and being a lone parent ( $0.6 \%$ of the single, childless women sample) and 253 women who move from lone-parent status to partnered status ( $7 \%$ of the lone parent sample).
} 
We specify three different models to analyse the effect of the reforms: (i) change in hours worked conditional on working before and after the reforms; (ii) the probability of being employed conditional on not working before the reform; and (iii) unconditional probability of employment.

\subsection{Changes in working hours for workers}

To investigate the possible channels through which hours adjustment occurs for lone mothers in response to the exogenous policy change, we specify an hours change model as Blundell et al. (2008), who also examine annual changes, as:

$$
\begin{aligned}
\Delta h_{i t+1} & =\alpha_{0}+\alpha_{1} L P_{i t}+\alpha_{2} J C_{i, t+1}+\alpha_{21} J C_{i, t+1} I(2004 \leq t<2006) \\
& +\alpha_{22} J C_{i, t+1} I(2006 \leq t<2009)+\left(\alpha_{31}+b_{1} L P_{i t}\right) I(2004 \leq t<2006) \\
& +\left(\alpha_{32}+b_{2} L P_{i t}\right) I(2006 \leq t<2009)+\beta_{1} L P_{i t} J C_{i, t+1} I(2004 \leq t<2006) \\
& +\beta_{2} L P_{i t} J C_{i, t+1} I(2006 \leq t<2009)+X_{i t}^{\prime} \gamma+\epsilon_{i t},
\end{aligned}
$$

where $L P_{t}$ indicates that the observation is a lone parent at time $t, I(w)$ is an indicator equal to 1 if condition $w$ is true, and $J C_{t+1}$ is an indicator for a job change between $t$ and $t+1 . \Delta h_{i t+1}$ denotes the change in total weekly hours worked between year $t$ and $t+1 ; X_{i t}$ is a vector of observables including levels measured at $t$ and the changes between $t$ and $t+1$; and $\epsilon_{i t}$ captures unobserved impacts on hours changes. $I(2004 \leq t<2006)$ and $I(2006 \leq t<2009)$ indicate the periods after the 2004 and 2006 reforms, respectively. Included in $X_{i t}$ are log wage, a quadratic polynomial in age, indicators for a stated desire to work more (underemployment) or work less (over-employment), industry dummies, number and their changes between $t$ and $t+1$ of children in four age groups ( 0 to $5 ; 6$ to 12 ; 13 to 15 ; and 16 to 17 ), type of work contract (casual or fixed term), time dummies, and local unemployment rates separately for each major urban area and at the state level for all other individuals outside the major urban areas. The variables 'underemployed' and 'over-employed' are included as indications of the deviation from the individual's preferred supply curve. Empirically, they also appear to have strong predictive power for hours changes. The model is estimated by ordinary least squares (OLS) over nine years for all observations where an individual works in two consecutive years. ${ }^{18}$

The equation is specified to investigate the role of changing jobs on changing hours and its interaction with the effect of the reforms. There are two sets of parameters that capture the effects of the reform. $b_{1}$ and $b_{2}$ capture the effects of the two reforms for workers who stayed in the same job. $\beta_{1}$ and $\beta_{2}$, meanwhile,

\footnotetext{
${ }^{18} \mathrm{We}$ also considered specifications where we included an interaction term for lone parents and job changes, but this was always insignificant. As there is no reason to believe that the probability of changing jobs differs for lone parents in the absence of the reform, we exclude this additional term.
} 
capture the additional effects of the two reforms on workers who changed jobs. If there were no within job hours restrictions, one would expect $\beta_{1}=\beta_{2}=0$. If this were true, it would indicate that lone parents could change their hours in response to the reforms by staying in the same job or by changing jobs in an equal manner. On the other hand, if $\beta_{1}>0$ (and similarly for the 2006 reforms), it would indicate a within-job hours restriction.

These four parameters are the difference-in-difference estimators for the two reforms estimated separately for the group who change jobs and for those who stay in the same job. As noted by Blundell et al. (2008), eq. (1) may suffer from an endogeneity problem if some omitted factor influences both the job change and the hours change. ${ }^{19}$ However, as they state, it helps provide an indication of the possible presence of imperfections or technological rigidities' in the labour market. By controlling for an individual's expressed desire to work more or less we reduce this source of endogeneity.

Equation (1) is a flexible specification with group-specific discrete jumps after the reforms for job stayers $\left(\alpha_{31}, \alpha_{32}, b_{1}\right.$, and $\left.b_{2}\right)$ and for job changers $\left(\alpha_{21}, \alpha_{22}, \beta_{1}\right.$, and $\beta_{2}$ ).

\subsection{Employment probability for non-workers}

The model for employment probability in the subsequent year of those who did not work at time $t\left(L_{i t}=0\right)$ is specified as

$$
\begin{aligned}
\operatorname{Prob}\left\{L_{i, t+1}=\right. & \left.1 \mid L_{i t}=0\right\}=F\left\{\eta_{0}+\eta_{1} L P_{i t}+\eta_{2} t+\eta_{31} I(2004 \leq t<2006)\right. \\
& +\phi_{1} L P_{i t} I(2004 \leq t<2006)+\eta_{32} I(2006 \leq t<2009) \\
& \left.+\phi_{2} L P_{i t} I(2006 \leq t<2009)+X_{i t}^{\prime} \mu\right\} .
\end{aligned}
$$

We estimate $F$ as a linear probability model (we use a probit specification in sensitivity tests); $\eta_{2}$ reflects a linear time trend common to both lone mothers and single, childless women; ${ }^{20}$ and $\eta_{31}$ and $\eta_{32}$ capture the shift in the employment probabilities after the reforms. $X_{i t}$ includes a quadratic polynomial in age, number and changes in the number between $t$ and $t+1$ of children in four age groups ( 0 to $5 ; 6$ to $12 ; 13$ to 15; and 16 to 17), English-language ability, and dummy variables for educational attainment and housing tenure (renter/ owner).

The key policy parameters are $\phi_{1}$ and $\phi_{2}$, which capture the treatment effects of the 2004 and 2006 reforms, respectively.

\footnotetext{
${ }^{19}$ Our eq. (1) is identical to eq. (4) in Blundell et al. (2008).

${ }^{20}$ As Francesconi and Klaauw (2004) point out, a more general specification would allow a different time trend for each group. However, given the limited number of waves, it would cause a collinearity problem and make the treatment effects impossible to identify. The time trend is not statistically significant and omitting it has no effect on our results.
} 


\subsection{Unconditional employment probability}

Our main focus is on the impact of the reforms on working hours of workers and increased employment probability of non-workers. To get a more complete picture of total employment, we also examine the unconditional probability of employment of all lone mothers and single, childless women as:

$$
\begin{aligned}
\operatorname{Prob}\left\{L_{i t}=1\right\} & =G\left\{\eta_{0}+\eta_{1} L P_{i t}+\eta_{2} t+\eta_{31} I(2004 \leq t<2006)\right. \\
& +\phi_{1} L P_{i t} I(2004 \leq t<2006)+\eta_{32} I(2006 \leq t<2009) \\
& \left.+\phi_{2} L P_{i t} I(2006 \leq t<2009)+X_{i t}^{\prime} \mu\right\}
\end{aligned}
$$

where $G$ is a linear probability function. One difference from eq. (2) is that the dependent variable is contemporaneous with the right-hand-side control variables. $X_{i t}$ contains the same set of control variables as eq. (2) with the exception of the changes in the number of children in different age groups.

\section{Data}

Data for the analysis are drawn from the first nine waves of the Household Income and Labour Dynamics in Australia Survey (HILDA) which cover the period 20012009. The HILDA Survey is an annual panel survey of Australian households which was begun in $2001 .^{21}$ There are approximately 7,000 households and 13,000 individuals who respond in each wave.

We focus on the labour supply of 946 lone mothers and 2,187 single, childless women of working age (between 15 and 64) excluding those who are permanently unable to work. ${ }^{22}$ This number also excludes a handful of observations with missing data on key variables. We are left with 11,628 observations, which we use to analyse the unconditional probability of employment (eq. (3)). For the analysis of hours changes for workers (eq. (1)), we restrict the sample to those whose status as lone parents or single, childless women is unchanged across two consecutive waves and who are working in those same two consecutive waves. This provides 4,384 observations on 1,388 women. The sample used to estimate the employment probability conditional on not working in the previous year (eq. (2)) consists of 2,340 observations on 830 women who remain in the same lone parent/single woman status in two consecutive waves and are not working in the first of those two waves.

Sample statistics are presented in Table 1. From the table, it can be seen that the characteristics of lone mothers are different from those of single, childless women. However, if we consider the subset of workers, they are more similar. The three primary occupations and industries are the same for the two groups, and roughly the same percentage of workers fall into these groups. Sole parents are slightly more

\footnotetext{
${ }^{21}$ See Watson and Wooden (2002) for more details.

${ }^{22}$ In an earlier version of the article, we excluded students and the self-employed. Those exclusions reduce the sample size by about $15 \%$, however, the results from making those exclusions are substantively the same as the results reported here.
} 
Table 1 Sample statistics

\begin{tabular}{|c|c|c|c|c|c|c|}
\hline \multirow[t]{2}{*}{ Variables } & \multicolumn{2}{|c|}{ Workers in $t$ and $t+1$} & \multicolumn{2}{|c|}{ Non-workers in $t$} & \multicolumn{2}{|l|}{$\begin{array}{l}\text { All } \\
\ldots \ldots . .\end{array}$} \\
\hline & $\begin{array}{l}\text { Lone } \\
\text { mothers }\end{array}$ & $\begin{array}{l}\text { Single } \\
\text { women }\end{array}$ & $\begin{array}{l}\text { Lone } \\
\text { mothers }\end{array}$ & $\begin{array}{l}\text { Single } \\
\text { women }\end{array}$ & $\begin{array}{l}\text { Lone } \\
\text { mothers }\end{array}$ & $\begin{array}{l}\text { Single } \\
\text { women }\end{array}$ \\
\hline Age & $38.7(7.4)$ & $40.2(13.6)$ & $35.7(8.9)$ & $50.8(14.0)$ & $36.7(8.6)$ & $41.1(15.3)$ \\
\hline Eng. 2nd tongue & 0.072 & 0.066 & 0.113 & 0.117 & 0.099 & 0.084 \\
\hline Tertiary edu. & 0.272 & 0.340 & 0.066 & 0.130 & 0.161 & 0.269 \\
\hline Vocational edu. & 0.338 & 0.277 & 0.310 & 0.182 & 0.327 & 0.249 \\
\hline Year 12 & 0.143 & 0.183 & 0.113 & 0.121 & 0.137 & 0.180 \\
\hline$<$ Year 12 & 0.247 & 0.200 & 0.511 & 0.567 & 0.375 & 0.302 \\
\hline Child. 0 and 5 & $0.343(0.55)$ & & $0.730(0.79)$ & & $0.556(0.73)$ & \\
\hline Child. 6 and 12 & $0.940(0.77)$ & & $0.966(0.96)$ & & $0.887(0.86)$ & \\
\hline Child. 13 and 15 & $0.383(0.55)$ & & $0.376(0.62)$ & & $0.367(0.581)$ & \\
\hline Child. 16 and 17 & $0.122(0.34)$ & & $0.113(0.34)$ & & $0.114(0.34)$ & \\
\hline Homeowner & 0.020 & 0.031 & 0.030 & 0.045 & 0.026 & 0.040 \\
\hline Home renter & 0.455 & 0.475 & 0.736 & 0.520 & 0.612 & 0.525 \\
\hline Mortgage payer & 0.525 & 0.494 & 0.234 & 0.435 & 0.362 & 0.435 \\
\hline Employed & & & 0.253 & 0.158 & 0.612 & $0.753(0.43)$ \\
\hline Hours of work & $29.4(13.2)$ & $37.4(12.6)$ & & & $29.3(14.1)$ & $36.2(13.7)$ \\
\hline$\Delta$ Hour & $1.116(7.86)$ & $0.137(8.72)$ & & & & \\
\hline$\Delta \mathrm{Job}$ & 0.144 & 0.176 & & & 0.159 & 0.195 \\
\hline Under-employed & 0.058 & 0.067 & & & 0.063 & 0.079 \\
\hline Over-employed & 0.208 & 0.288 & & & 0.200 & 0.268 \\
\hline Wage (\$2001) & $18.550(9.05)$ & $18.788(7.88)$ & & & $18.165(9.78)$ & $18.293(8.92)$ \\
\hline Permanent job & 0.621 & 0.707 & & & 0.587 & 0.678 \\
\hline Fixed-term job & 0.091 & 0.101 & & & 0.088 & 0.096 \\
\hline Casual job & 0.288 & 0.192 & & & 0.325 & 0.226 \\
\hline \multicolumn{7}{|l|}{ Industry } \\
\hline \multicolumn{7}{|l|}{ Health Care and } \\
\hline Social Assistance & 0.280 & 0.242 & & & & \\
\hline Education & & & & & & \\
\hline and Training & 0.161 & 0.143 & & & & \\
\hline Retail Trade & 0.117 & 0.111 & & & & \\
\hline \multicolumn{7}{|l|}{ Occupation } \\
\hline Professionals & 0.276 & 0.308 & & & & \\
\hline Clerical & 0.218 & 0.237 & & & & \\
\hline \multicolumn{7}{|l|}{ Community and } \\
\hline Personal Service & 0.205 & 0.151 & & & & \\
\hline Obs. & 985 & 3,399 & 914 & 1,426 & 3,332 & 8,296 \\
\hline
\end{tabular}

Notes: Standard deviations are in parentheses; job-related characteristics are for workers only. Level variables are for $t$; changes are from $t$ to $t+1$; the rate of employment of nonworkers is for $t+1$. 'Workers in $t$ and $t+1^{\prime} /$ 'Non-workers' are conditional on being lone mothers/single women in both $t$ and $t+1$.

represented in the 'health care and social assistance' industry and slightly less present in 'education and training' than single, childless women. Single, childless women are slightly more likely to be professionals and slightly less likely to be sales workers than are single mothers. Overall, as expected, lone mothers are less 


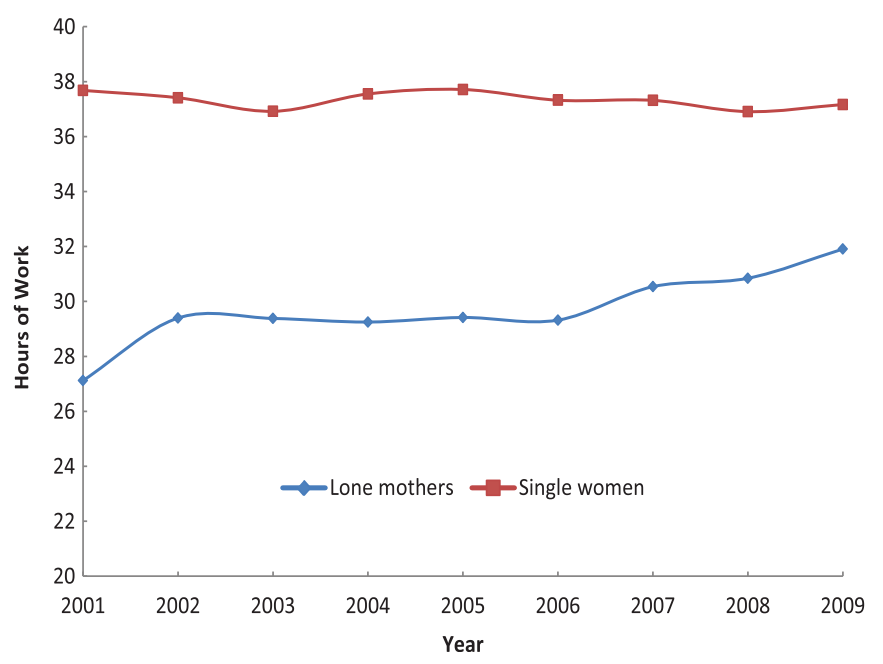

Fig. 3 Hours of work at time $t$ for those who work at both time $t-1$ and $t$.

educated, younger, and more likely to be renters. They are also less likely to participate in the labour force and, when they do work, work fewer hours. The biggest difference is between the non-working lone mothers and their single, childless counterparts. The latter group is much older (with average age of 53 years). This may invalidate one of our identification requirements. We check this by restricting the age of the comparison group to 50 or less in one of the sensitivity tests. The lone parents and single, childless women who work are more comparable in their characteristics, and they are better educated than the non-workers. However, their labour supply differs. The lone mothers are more often casual workers, work fewer hours, and are less likely to report being under- or over-employed.

Figures 3 through 6 compare the labour supply of lone mothers and single, childless women. We can see that labour supply differs by group. In Figs 3 and 4 , we plot average hours of work and the change of hours for those who work in two consecutive time periods. Figure 3 shows the working hours for those who work both in the current period and the previous period. In 2001, lone mothers who reported working in both 2000 and 2001 worked an average of 27 hours in 2001. In Fig. 4, we graph the change in hours looking forwards. For lone mothers who worked in 2001 and also worked in 2002, time worked increased on average by just over one hour from 2001 to 2002. Consistent with Fig. 1, Figs 3 and 4 show that lone mothers' hours of work increased in the second half of the last decade but those of single, childless women remained fairly stable. Figure 4 shows that the change of hours for lone mothers are positive except in 2002 and are more volatile than the changes in hours of single, childless women. The eye is attracted to the oscillations in this graph, but given the $y$-axis scale, these are small. ${ }^{23}$ The main

\footnotetext{
${ }^{23}$ Only the difference for lone mothers from 2005 to 2006 is statistically significant at the $5 \%$ level if we look at year-on-year changes for the two groups.
} 


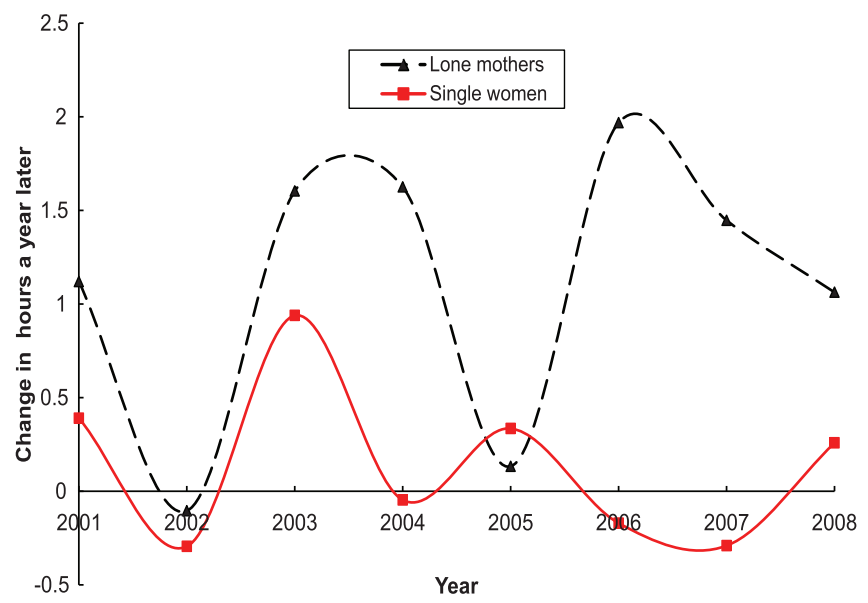

Fig. 4 Changes in hours between $t$ and $t+1$ for those who work at both $t$ and $t+1$.

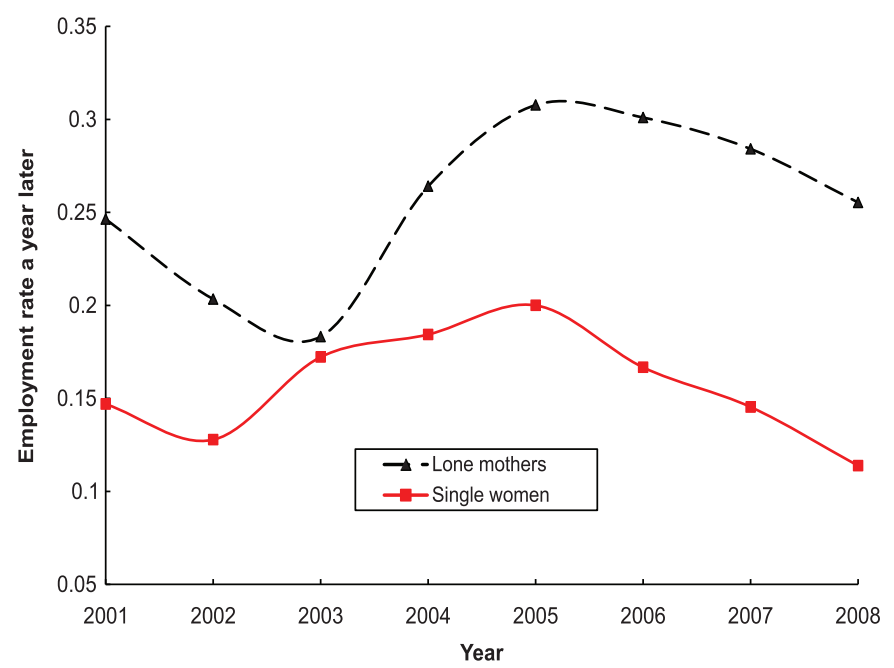

Fig. 5 Employment rate each year for those who did not work in the previous year.

point from the graph is that the year-on-year changes are generally larger for lone mothers than for single women. If we statistically test the pointwise differences, taking into account the correlation across time, the points on the line (the changes in hours worked) are statistically different for lone mothers and single, childless women for 2004, 2006, and 2007, which correspond to the reform years.

Figure 5 shows employment rates at each period conditional on not working in the previous period. For those who didn't work in 2000, 15\% of single, childless women were employed in 2001. Future employment rates for non-working lone 


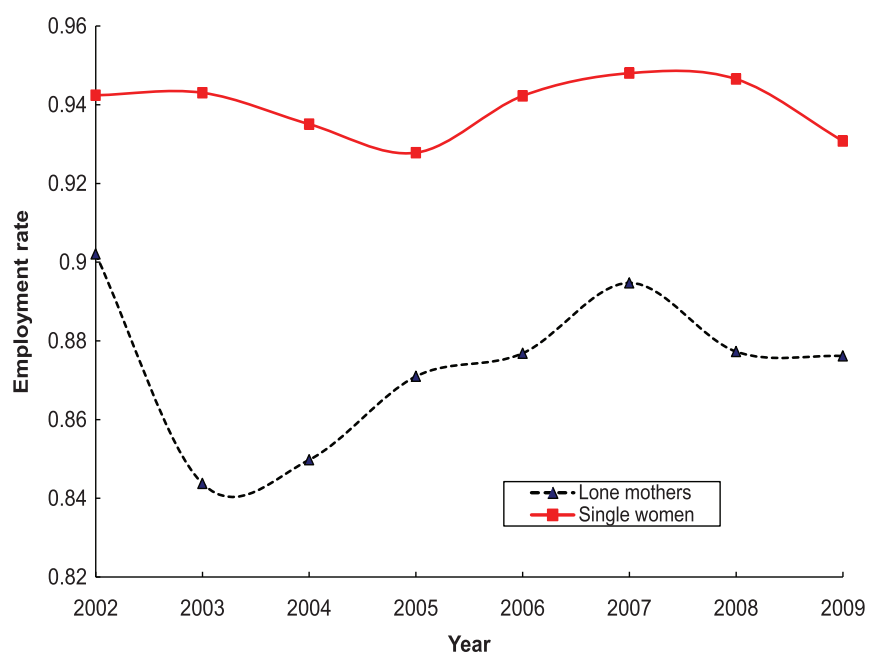

Fig. 6 Employment rate at for those who were employed in the previous year.

mothers are a bit higher since 2005 and the pattern is different from that of single, childless women. From Fig. 6, however, we can see that the difference in the patterns of remaining employed for workers is less pronounced. Nonetheless, lone mothers are less likely to stay in employment than are single, childless women. In the appendix, Figure A2 plots employment rates for single women and lone mothers in our data. This figure confirms the overall increase in lone mothers' employment across our sample period.

\section{Results}

We estimate each model for the full sample and also for various sub-samples partitioned by mother's education, number of children, and age of youngest child to analyse potential heterogeneity of policy effects. For the sake of conciseness, we only report the main parameter estimates. Full regression results are available on request.

\subsection{Channel of hours adjustment for workers}

Parameter estimates of the treatment effects of the reforms are presented in Table 2. In the first column we present results from estimation on the full sample with the remaining columns providing estimates on selected sub-samples of interest.

For those who stay in their jobs we find no effect of the 2004 reform on working hours. For those that change jobs, we find a positive and statistically significant effect of the reform. Working mothers who changed jobs increased their hours of work by 4.1 hours per week $\left(b_{1}+\beta_{1}\right)$ in response to the reforms. Looking further across the table, we can see that the effect of the 2004 reform is not constant across all sub-populations. The effect appears stronger for women with fewer and older 
Table 2 Effects of the reforms and job changes on hours worked

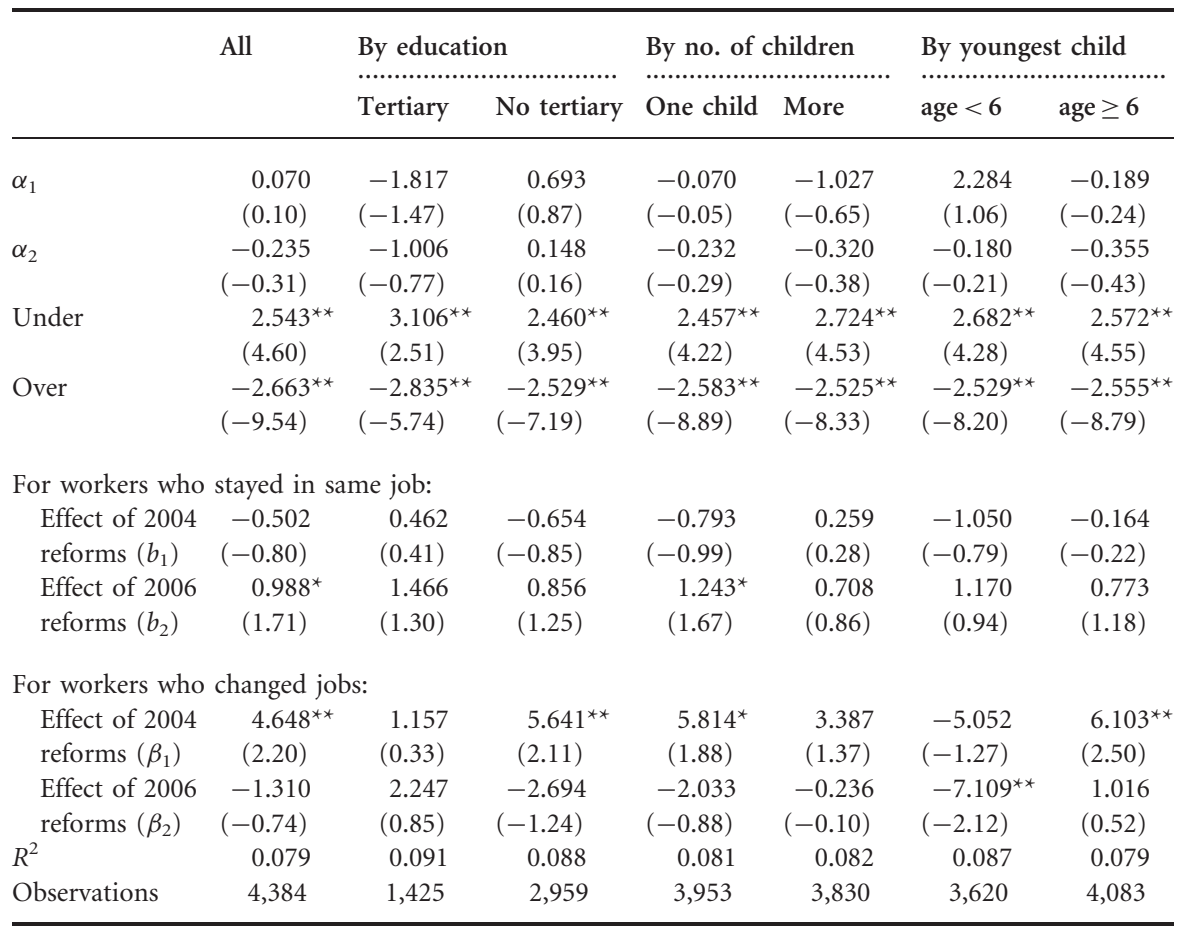

Notes: $t$-values calculated using robust standard errors clustered at the level of the individual are in parentheses. Clustering at both occupation and individual level produces similar results. ${ }^{*}$ Significant at $10 \%$ level. ${ }^{* *}$ Significant at $5 \%$ level.

children, who likely face lower costs to work additional hours. We also find a significant and stronger effect for women without tertiary education. These women have lower wages and are more likely to fall in the region on Fig. 2 where earnings are affected by the change in taper rates.

For the 2006 reforms, we find a small (about one-hour) positive effect across the whole sample. The sub-groups for whom we find the largest effect are tertiaryeducated women who change jobs $\left(3.7\right.$ hours $\left.^{24}\right)$ and women with only one child who stay in the same job (1.2 hours). Even before the reforms, women with tertiary education earn more and use more child care. CCTR is not means-tested and is only valuable when there is a tax liability to be offset. Thus the value of CCTR is highest for these women. ${ }^{25}$ Women with only one child may find it easier to increase their hours than would those with many children. The changes to PPS

\footnotetext{
${ }^{24}$ The $p$-value for the sum of the two coefficients is 0.16 .

${ }^{25}$ This result is consistent with Gong and Breunig (2012), who simulated the ex ante effects of CCTR with a structural child care and labour supply model.
} 
Table 3 Effects of the reforms on participation of non-workers

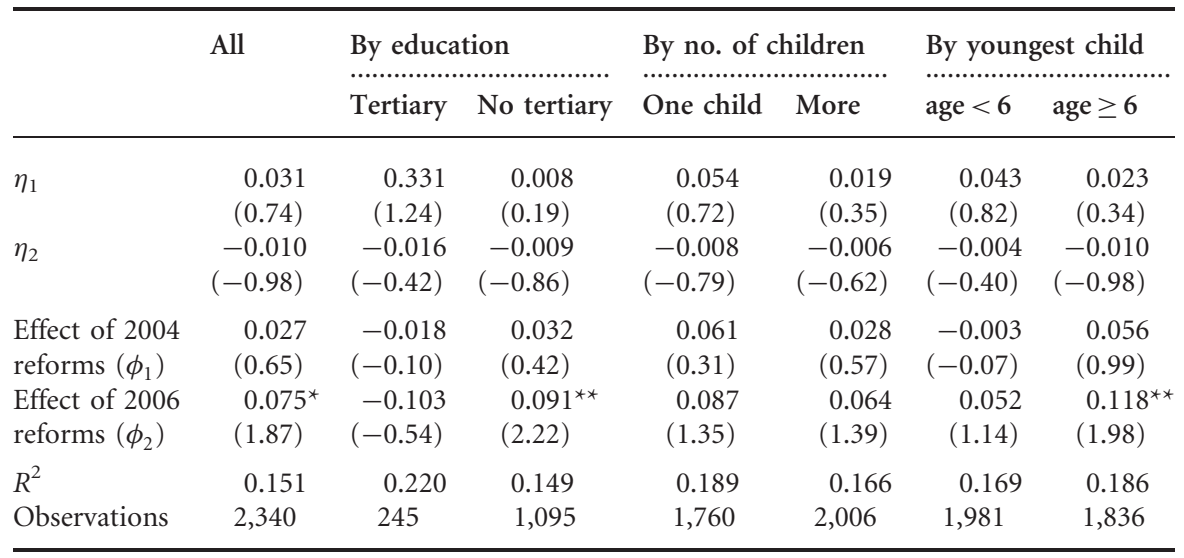

Notes: $t$-values calculated using robust standard errors are in parentheses. ${ }^{*}$ Significant at $10 \%$ level. $* *$ Significant at $5 \%$ level.

eligibility were not expected to influence working hours for workers because women who were already working were not affected by these reforms. So in the case of changes in working hours for those already working, our evaluation of the 2006 reforms can be considered an evaluation of the introduction of CCTR. The large negative coefficient associated with changing jobs for women with young children is surprising. Women with young children who change jobs appear to decrease working hours in response to the 2006 reforms by about six hours. This could be an income effect from CCTR for this sub-group.

We can also see from Table 2 that a reported desire to change work hours is highly predictive of future hour changes. Those who report wanting to work more increase their work hours by 2.5 hours a week on average relative to those who are satisfied with their hours, whereas those who report wanting to work less decrease their work hours by 2.6 hours a week on average relative to those who are satisfied with their hours.

Overall, the results provide evidence that there are within-job hour restrictions in the Australian labour market. Changing jobs appears to be an important channel for all workers to respond to the 2004 policy reforms. It is also the primary channel by which higher educated workers respond to the 2006 reforms.

\subsection{Subsequent employment of non-workers}

Table 3 summarizes the key parameter estimates for non-workers' subsequent employment probability. The statistical significance of $\phi_{2}$ and the insignificant $\phi_{1}$ coefficient indicate that the 2006 reforms had a positive effect on the future employment probability of non-workers but the 2004 reforms had no effect. This is consistent with our expectations. The 2006 reforms lowered the cost of working through the introduction of CCTR and also tightened rules and activity tests for 
Table 4 Estimates of unconditional participation of all lone mothers

\begin{tabular}{|c|c|c|c|c|c|c|c|}
\hline & \multirow[t]{2}{*}{ All } & \multicolumn{2}{|c|}{ By education } & \multicolumn{2}{|c|}{ By no. of children } & \multicolumn{2}{|c|}{ By youngest child } \\
\hline & & Tertiary & No tertiary & One child & More & age $<6$ & age $\geq 6$ \\
\hline$\eta_{1}$ & $\begin{array}{l}-0.060^{\star *} \\
(-2.08)\end{array}$ & $\begin{array}{r}0.060 \\
(1.07)\end{array}$ & $\begin{array}{l}-0.100^{* *} \\
(-3.04)\end{array}$ & $\begin{array}{l}-0.054 \\
(-1.47)\end{array}$ & $\begin{array}{l}-0.094^{\star *} \\
(-1.99)\end{array}$ & $\begin{array}{l}-0.141^{\star \star} \\
(-3.30)\end{array}$ & $\begin{array}{c}-0.034 \\
(-0.79)\end{array}$ \\
\hline$\eta_{2}$ & $\begin{array}{r}0.003 \\
(0.78)\end{array}$ & $\begin{array}{l}-0.004 \\
(-0.65)\end{array}$ & $\begin{array}{r}0.003 \\
(0.75)\end{array}$ & $\begin{array}{c}0.001 \\
(0.21)\end{array}$ & $\begin{array}{l}-0.002 \\
(-0.52)\end{array}$ & $\begin{array}{r}0.001 \\
(0.17)\end{array}$ & $\begin{array}{c}0.002 \\
(0.42)\end{array}$ \\
\hline $\begin{array}{l}\text { Effect of } 2004 \\
\text { reforms }\left(\phi_{1}\right)\end{array}$ & $\begin{array}{r}0.021 \\
(0.92)\end{array}$ & $\begin{array}{r}0.005 \\
(0.10)\end{array}$ & $\begin{array}{r}0.030 \\
(1.16)\end{array}$ & $\begin{array}{l}-0.021 \\
(-0.67)\end{array}$ & $\begin{array}{l}0.061^{\star *} \\
(2.01)\end{array}$ & $\begin{array}{l}-0.009 \\
(-0.23)\end{array}$ & $\begin{array}{l}0.046^{\star} \\
(1.68)\end{array}$ \\
\hline $\begin{array}{l}\text { Effect of } 2006 \\
\text { reforms }\left(\phi_{2}\right)\end{array}$ & $\begin{array}{l}0.056^{* \star} \\
(2.20)\end{array}$ & $\begin{array}{r}0.066 \\
(1.39)\end{array}$ & $\begin{array}{l}0.056^{*} \\
(1.90)\end{array}$ & $\begin{array}{r}0.042 \\
(1.25)\end{array}$ & $\begin{array}{l}0.073^{\star *} \\
(2.22)\end{array}$ & $\begin{array}{l}-0.027 \\
(-0.73)\end{array}$ & $\begin{array}{l}0.085^{\star *} \\
(2.71)\end{array}$ \\
\hline$R^{2}$ & 0.229 & 0.128 & 0.213 & 0.217 & 0.246 & 0.252 & 0.209 \\
\hline Observations & 11,628 & 2,763 & 8,865 & 9,841 & 10,083 & 9,737 & 10,187 \\
\hline
\end{tabular}

Notes: $t$-values calculated using robust standard errors are in parentheses. ${ }^{\star}$ Significant at $10 \%$ level. ** Significant at $5 \%$ level.

receipt of PPS, which had the effect of pushing people into a choice between a lower payment (NSA) or employment. The combination of these two should have a clear employment incentive that is particularly concentrated amongst lone mothers who are less educated and have older children, as can be seen from the other columns of Table 3. The 2004 reform did not have a particularly strong employment incentive for those not already employed, and our insignificant parameter estimate can be interpreted as an indication that the modest improvements to work incentives were outweighed to a great degree by fixed costs of working for non-workers.

\subsection{Unconditional employment of all lone mothers}

Table 4 presents estimates of the unconditional employment probability. The estimates for the full sample of $\phi_{1}$ and $\phi_{2}$ show a similar tendency as the findings in Section 5.2: no employment effects associated with the 2004 reforms but some employment effects associated with the 2006 reforms.

\subsection{Sensitivity tests}

To check for selection effects, functional form, the validity of the common support assumption, whether we are actually identifying an effect of the reforms, and the potential effect of other factors, we conducted a range of sensitivity tests for each of the estimated equations. These are summarized in Appendix Tables 5 through 9.

In the working hours and conditional employment equations we controlled for the level and the change in the number of children in each age group. Yet aging of children could still confound the estimated treatment effect. ${ }^{26}$ To further reduce the

\footnotetext{
${ }^{26}$ Appendix Figure A3 shows the strong relationship between employment rates for lone mothers and the age of their youngest child.
} 
impact of children's aging (although we can never completely remove it), we restrict the sample to observations in which the youngest child remains in the same age group at $t$ and $t+1$. Second, to check whether there is a problem caused by non-random attrition, we restrict the sample to individuals who were observed in at least six waves. Third, we estimate the model excluding the ninth wave. Because CCTR changed (it was increased from 30\% to 50\% as of July 2008) and the onset of the global financial crisis may have affected our two groups differently, the ninth wave may be quite different from other waves. These results, presented in Appendix Tables 5, 7, and 9 show that our results are robust to these changes.

Including many covariates in the models may make it harder to find overlapping groups with the same characteristics in both the treatment and control groups. In the treatment literature this is called the common support problem. To see whether this affects our results, we combine the difference-in-difference estimator with propensity score matching. We re-estimated eqs (2) and (3) with local linear regression matching (see, for example, Heckman et al., 1997; Fan, 1992). ${ }^{27}$ For each equation, we report two different propensity score matching estimators. The column labeled PSM1 in Appendix Tables 6 and 8 uses a matching equation with the regressors that are used in eqs (1), (2), and (3), respectively. These fail the balancing test proposed by Dehejia and Wahba (1999) (we use the implementation of Becker and Ichino, 2002). The column labelled PSM2 uses a restricted set of covariates (wave dummies, age, and education level only) for which the balancing test always passes for all equations and all sub-groups. Lee (2013) discusses the shortcomings of the balancing test, in particular, that it may require different specifications for different sub-samples. The key insights from Appendix Tables 6 and 8 are that the use of matching does not change our conclusions from the regression models nor does changing the specification of the matching equation.

We estimate all of our models without any control variables. We also estimate eq. (2) with the comparison group restricted to be 50 years of age or younger given the differences between the average age of the treatment and control groups as discussed. We estimate the employment probability equations using a probit functional form. These are reported in Appendix Tables 5, 7, and 9.

The important identifying condition of our model is the common trends assumption-that is, that the untreated response changes are the same across the treatment and control groups. It may be that we are picking up the effect of differential changes in hours and employment between lone mothers and single women and that this is unrelated to the reforms. A natural way to check this is to re-estimate the model but assign the 'reform' spuriously to the wrong time period. This is often referred to in the literature as a placebo test. We do this by changing the time dummies in eqs (1) through (3). We replace $I(2004 \leq t<2006)$ with $I(2003 \leq t<2005)$ and $I(2006 \leq t<2009)$ with $I(2005 \leq t<2009)$. This is

\footnotetext{
${ }^{27}$ For eq. (1) only, we used linear regression matching as the number of observations in each cell is too small to undertake a non-parametric approach.
} 
akin to estimating the model as if the reforms took place in 2003 and 2005 instead of 2004 and 2006. If we are simply picking up the effect of some underlying differences in the two groups then we should find significant differences even when we mis-specify the timing of the reforms.

For our impact estimates on working hours (Appendix Table 5) and the probability of employment conditional on not working in the previous period (Appendix Table 7) we find the placebo test is insignificant. Our impact estimates appear to be related to the reforms. For the unconditional participation estimates (Appendix Table 9), we find that the placebo test is significant at the 10\% level. These estimates of participation are not conditional on parental status or employment status across waves. As already discussed, our unconditional estimates of employment probabilities support our main findings although the placebo test indicates that they may also be picking up other changes in the labour market or policy environment.

Appendix Table 10 presents results using married mothers, instead of single, childless women, as a control group. For the 2004 reforms, this can be viewed as another placebo test, as the changes of those reforms applied equally to married mothers. Indeed, we find no statistically significant differences between married and lone mothers from the 2004 reforms. The 2006 reforms were different in that they affected both groups, but the incentive effects for additional workforce participation were much stronger for lone mothers than for married mothers (see Section 2.2). We find no differential effect on working hours for married and single women; however, we do find that lone mothers increased participation (both conditional on not working and unconditionally) relative to married mothers. This is reassuring because we would expect this effect to be stronger for lone mothers. What we cannot sort out is whether these differences are due to the larger changes to PPS relative to PPP or whether lone and married mothers responded differently to the child care tax rebate.

\section{Conclusions}

Our article illustrates the relationship between different policy designs and heterogeneous labour supply outcomes for lone mothers. We find that two reforms that changed the work incentives for lone mothers in Australia increased working hours of those who were working and employment of non-workers. The adjustment in working hours was largely through changing employers in an environment where working hours are often constrained within jobs. The 2004 reform had positive effects on hours of work by working lone mothers, but only through job changes. The effects were concentrated amongst lone mothers with lower education and with fewer and older children. The 2006-7 reforms contributed to an increased probability of employment in subsequent periods for those who were not working prereform. Again, effects were concentrated amongst lone mothers with lower education and older children. 
One qualification to our results comes from the use of childless women as a control group. Childless women start with much higher labour force participation rates, so their ability to respond to increased labour demand in Australia throughout the period we study may be more limited than that of single mothers. This may cause our approach to overstate the effect of the reforms on lone parents' labour supply. However, our robustness checks and placebo tests indicate that something is happening to lone mothers that is contemporaneous with the reforms. It appears that the reforms had some effect on lone mothers, but our actual numerical estimates of the impact of the reform should be used with caution for this reason and the usual reasons of statistical uncertainty.

These results highlight some caveats to the usual application of the standard model. First, some reforms, with only small work incentives, seem to have little effect on participation. This is consistent with important fixed costs of working which should be accounted for when modelling labour supply. Second, in-work rigidities appear to exist. The ability of policy changes to induce working hour changes therefore may be enhanced or diminished by the degree of dynamism in the labour market. Policies that make working more attractive for those already earning some income change incentives for workers, but not for non-workers. The 2004 reforms are primarily of this type. The 2006-7 reforms, on the other hand, by tightening welfare eligibility rules, change incentives mostly for those who are not working. We show that for these reforms, hours are relatively unchanging whereas the large effects are on non-workers with older children and without tertiary education.

\section{Supplementary material}

Supplementary material (the Appendix) is available online at the OUP website.

\section{Acknowledgements}

We thank the editor and two anonymous referees whose thoughtful comments helped us to improve the article.

\section{References}

Altonji, J.G. and Paxson, C.H. (1988) Labour supply preferences, hours constraint, and hours-wage tradeoffs, Journal of Labor Economics, 6, 254-76.

Altonji, J.G. and Paxson, C.H. (1992) Labour supply, hours constraint, and job mobility, Journal of Human Resources, 27, 256-78.

Angrist, J. and Kruger, A. (1999) Empirical stragegies in labor economics, in O. Ashenfelter and D. Card (eds) Handbook of Labor Economics, vol. 3A, Elsevier Science, Amsterdam.

Ashenfelter, O.C. (1978) Estimating the effect of training programs on earnings, Review of Economics and Statistics, 60, 47-57. 
Becker, S.O. and Ichino, A. (2002) Estimation of average treatment effects based on propensity scores, Stata Journal, 2, 358-77.

Blundell, R., Brewer, M., and Francesconi, M. (2008) Job changes and hours changes: understanding the path of labor supply adjustment, Journal of Labor Economics, 26, 421-53.

Blundell, R., Brewer, M., and Shephard, A. (2005) Evaluating the labour market impact of working families' tax credit using difference-in-differences, Open access publications, University College London, http://discovery.ucl.ac.uk.

Blundell, R. and MaCurdy, T.E. (1999) Labour supply: a review of alternative approaches, in O. Arshenfelter and D. Card (eds) Handbook of Labor Economics, vol. 3A, Elsevier Science, Amsterdam.

Brewer, M., Duncan, A., Shephard, A., and Suárez, M.J. (2006) Did working families' tax credit work? The impact of in-work support on labour supply in Great Britain, Labour Economics, 13, 699-720.

Card, D. and Robins, P.K. (1998) Do financial incentives encourage welfare recipients to work? Research in Labor Economics, 17, 1-56.

Dehejia, R. and Wahba, S. (1999) Causal effects in non-experimental studies: re-evaluating the evaluation of training programs, Journal of the American Statistical Association, 94, 1053-62.

Doiron, D.J. (2004) Welfare reform and the labour supply of lone parents in Australia: a natural experiment approach, Economic Record, 80, 157-76.

Eissa, N. and Hoynes, H. (2004) Taxes and the labor market participation of married couples: the earned income tax credit, Journal of Public Economics, 88, 1931-58.

Eissa, N. and Liebman, J.B. (1996) Labor supply response to the earned income tax credit, Quarterly Journal of Economics, 112, 605-37.

Ellwood, D.T. (2000) The impact of the earned income tax credit and social policy reforms on work, marriage, and living arrangements, National Tax Journal, 53, 1063-106.

Euwals, R. (2001) Female labour supply, flexibility of working hours, and job mobility, Economic Journal, 111, C120-34.

Fan, J. (1992) Design-adaptive nonparametric regression, Journal of the American Statistical Association, 87, 998-1004.

Fok, Y.K. and McVicar, D. (2012) Did the 2007 welfare reforms for low income parents in Australia increase welfare exits? Melbourne Institute Working Paper Series wp2012n01.

Francesconi, M. and Klaauw, W.V.D. (2004) The consequences of 'in-work' benefit reform in Britain: new evidence from panel data, ISER Working Paper no. 2004-13, University of Essex.

Francesconi, M. and Klaauw, W.V.D. (2007) The socioeconomic consequences of 'in-work' benefit reform for British lone mothers, Journal of Human Resources, 42, 1-31.

Gong, X. and Breunig, R. (2012) Child care assistance: are subsidies or tax credits better? IZA Discussion Paper no. 6606; available at http://ftp.iza.org/dp6606.pdf.

Gregg, P. and Harkness, S. (2003) Welfare reform and lone parents employment in the UK, CMPO Working paper series No. 03/072, Department of Economics, University of Bristol.

Ham, J.C. (1982) Estimation of a labour supply model with censoring due to unemployment and underemployment, Review of Economic Studies, 49, 335-54. 
Heckman, J.J., Ichimura, H., and Todd, P.E. (1997) Matching as an econometric evaluation estimator: evidence from evaluating a job training programme, Review of Economic Studies, 64, 605-54.

Heckman, J.J. and Robb, R. (1985) Alternative methods for evaluating the impact of interventions, in J.J. Heckman and B.S. Singer (eds) Longitudinal Analysis of Labor Market Data, Econometric Society Monograph Series no. 10, Cambridge University Press, Cambridge.

Hotz, J.V. and Scholz, J.K. (2003) The earned income tax credit, in R.A. Moffitt (ed.) MeansTested Transfer Programs in the United States, University of Chicago Press, Chicago, IL.

Hotz, V.J., Mullin, C.H., and Scholz, J.K. (2002) Welfare, employment, and income: evidence on the effects of benefit reductions from California, American Economic Review, 92, 380-84.

Kalb, G.R. (2010) Modelling labour supply responses in Australia and New Zealand, in I. Claus, N. Gemmell, M. Harding, and D. White (eds) Tax Reform in Open Economies: International and Country Perspectives, Edward Elgar, Cheltenham.

Lee, W.-S. (2013) Propensity score matching, Empirical Economics, 44, 47-80.

Leigh, A.K. (2005) Optimal design of earned income tax credits: evidence from a British natural experiment, CEPR Discussion Papers 488, Centre for Economic Policy Research, Research School of Economics, Australian National University, Canberra.

Lundberg, S. (1985) Tied wage-hours offers and the endogeneity of wages, Review of Economics and Statistics, 67, 405-10.

Meyer, B.D. (1995) Natural and quasi-experiments in economics, Journal of Buiness and Economic Statstics, 13, 151-61.

Moffitt, R.A. (1984) The estimation of a joint wage-hours labor supply model, Journal of Labor Economics, 2, 550-66.

Parr, N. and Guest, R. (2011) The contribution of increases in family benefits to Australia's early 21st-century fertility increase: an empirical analysis, Demographic Research, 25, 215-44.

Stewart, M.B. and Swaffield, J.K. (1997) Constraints on the desired hours of work of British men, Economic Journal, 107, 520-35. 